\title{
La circulación del esoterismo en América Latina. El conde de Das y sus viajes por Argentina y Perú, 1892-1900
}

Resumen: Este artículo examina la trayectoria profesional de Alberto Santini Sgaluppi, o conde de Das, un esoterista que se presentó en Buenos Aires y Lima a fines del siglo XIX, y el impacto de sus espectáculos entre diversos actores sociales en ambas capitales sudamericanas. Argumentamos que individuos como Sgaluppi jugaron un rol esencial en la difusión de conocimientos y fenómenos ligados con el esoterismo y la hipnosis, y que el estudio de sus emprendimientos puede iluminar el desarrollo de los discursos científicos y de los contornos de conocimientos definidos como "ciencia" en la esfera pública y más allá de círculos de expertos.

Palabras clave: historia de la ciencia, historia de la medicina, esoterismo, espiritismo, hipnosis.

\section{The circulation of esoterism in Latin America. The conde de Das and his travels through Argentina and Peru, 1892-1900}

Abstract: This paper examines the professional trajectory of Alberto Santini Sgaluppi ["conde de Das"], an esoterist who performed in Buenos Aires and Lima in the late nineteenth century and analyzes the impact of his spectacles on diverse social actors in the two South American capital cities. We argue that individuals like Sgaluppi played a pivotal role in the spread of knowledge about nascent phenomenons linked to esoterism and hypnotism; at the same time, a close examination of his performances throws light on the development of scientific discourses and on the contours of "science" in the public sphere, beyond the conventional circle of experts.

Keywords: history of science, history of medicine, esoterism, spiritism, hypnotism.

\section{A circulação do esoterismo na América Latina. 0 conde de Das e seus viagens pela Argentina e Peru, 1892-1900}

Resumo: Este artigo examina a trajetória profissional de Alberto Santini Sgaluppi, ou conde de Das, esoterista que se apresentou em Buenos Aires e Lima no final do século XIX, e o impacto de seus espetáculos entre os diversos atores sociais de ambas as capitais sul-americanas. Argumentamos que indivíduos como Sgaluppi desempenharam um papel essencial na disseminação de conhecimento e fenômenos ligados ao esoterismo e à hipnose, e que o estudo de seus esforços pode iluminar o desenvolvimento de discursos científicos e os contornos de conhecimento definidos como "ciência" na esfera pública e para além dos círculos de especialistas.

Palavras-chave: história da ciência, história da medicina, esoterismo, espiritismo, hipnose.

Cómo citar este artículo: Patricia Palma y Mauro Vallejo, "La circulación del esoterismo en América Latina. El conde de Das y sus viajes por Argentina y Perú, 1892-1900”, Trashumante. Revista Americana de Historia Socia/14 [2019]: 6-28. DOI: 10.17533/udea.trahs.n14a01

Fecha de recepción: 8 de agosto de 2018

Fecha de aprobación: 30 de enero de 2019

Patricia Palma: Doctora en Historia por la University of California. Investigadora postdoctoral de la Pontificia Universidad Católica de Chile.

Correo electrónico: pnpalma@uc.cl

Mauro Vallejo: Doctor en Psicología por la Universidad Nacional de La Plata. Investigador del Consejo Nacional de Investigaciones Científicas y Técnicas [CONICET].

Correo electrónico: maurosvallejo@gmail.com 


\title{
La circulación del esoterismo en América Latina. El conde de Das y sus viajes por Argentina y Perú, 1892-1900
}

\author{
Patricia Palma y Mauro Vallejo
}

Introducción

En los últimos años, el estudio de los fenómenos psíquicos y espiritistas ha ganado

Emayor presencia en las investigaciones históricas referidas a la producción del conocimiento científico en América Latina. Por mucho tiempo marginada por la historiografia de la ciencia y de la medicina, pues era considerada como un corpus ajeno a lo que hoy en día sería incluido en el terreno de lo "científico", la literatura esotérica tuvo una fuerte repercusión en los idearios y saberes compartidos por la élite y los sectores medios durante los siglos XIX y XX. Médicos, escritores, intelectuales y masones, e incluso científicos, participaron activamente en seminarios y espectáculos espiritistas, hipnotistas y parasicológicos en los que alentaban candentes discusiones sobre los límites de la ciencia. De esta forma, el análisis de la difusión del espiritismo y de los fenómenos psíquicos constituye una herramienta importante y poco explorada para replantear la construcción del conocimiento científico y la naturaleza misma de la ciencia en América Latina.

Pese a que Annette Mülberger ha insistido en la vocación internacional que tuvo el espiritismo, hasta hoy su estudio continúa restringido a los límites nacionales. ${ }^{1}$ A ello es necesario agregar que la mayoría de las investigaciones referidas al espiritismo y otras prácticas como la hipnosis y el magnetismo permanecen enfocadas en la experiencia europea y norteamericana. ${ }^{2}$ Con la intención de

1. Annette Mülberger, ed., Los límites de la ciencia. Espiritismo, hipnotismo y el estudio de los fenómenos paranormales (1850-1930) (Madrid: Consejo Superior de Investigaciones Científicas, 2016) 19.

2. Para un balance sobre la literatura histórica referida al esoterismo europeo, véase Andrea Graus, "La ciencia del médium. Las investigaciones psíquicas en España" (Tesis de doctorado en Historia de la Ciencia, Universidad Autónoma de Barcelona, 2014). Las investigaciones sobre esoterismo, espiritismo y ocultismo en América Latina son abundantes, especialmente para el caso de Argentina y Brasil; véase Soledad Quereilhac, Cuando la ciencia despertaba fantasías. Prensa, literatura y ocultismo en la Argentina de entresiglos (Buenos Aires: Siglo XXI, 2016); Juan Pablo Bubello, Historia del esoterismo en la Argentina. Prácticas, representaciones y persecuciones de curanderos, espiritistas, astrólogos y otros esoteristas (Buenos Aires: Biblos, 2010); Emerson Giumbelli, O Cuidado dos Mortos: Uma 
revertir esta situación, este artículo estudia una dimensión particular de la historia transnacional del espiritismo y otros fenómenos psíquicos en América Latina en el cambio de siglo. Nuestro objetivo es poner de relieve el rol protagónico que tuvieron ciertos agentes en la labor de difusión regional de vocabularios, doctrinas y teorías esotéricas. En efecto, dada su vocación internacional, la historia de esas doctrinas heterodoxas debe ser abordada con base en el estudio de los circuitos, procesos y actores sociales que promovieron y garantizaron la circulación constante de saberes y experiencias.

En tal sentido, este artículo busca documentar las labores realizadas por uno de los principales promotores regionales de esas doctrinas heterodoxas. Nos referimos a Alberto Santini Sgaluppi — también conocido como conde de Das, Alberto Martínez de Das, conde de Sarak, Albert Sarak, entre muchos otros apelativos-, un ocultista de origen italiano que entre 1892 y 1906 recorrió de modo incansable diversos países del continente, y llevó a cabo una labor sostenida de difusión de idearios esotéricos. Durante esos casi 15 años, Santini Sgaluppi vivió por períodos más o menos prolongados en Argentina, Uruguay, Chile, Perú, México y Estados Unidos, y en las principales ciudades de esos países fundó institutos y revistas, ofrecía cursos, conferencias y demostraciones con lo que se transformó en un temprano promotor del ocultismo, el espiritismo y la teosofia en la región.

En cada una de esas urbes supo ganar adeptos y detractores, y en cada una de ellas captó la atención del mundo letrado, especialmente de los médicos. Por lo tanto, el estudio de sus trabajos permite iluminar no solo la relevancia que tuvieron los viajes de esos ocultistas nómadas en la circulación regional de conocimientos y teorías, sino también las reacciones y recibimientos de las iniciativas esotéricas en diferentes contextos. En esta ocasión, en particular, haremos una reconstrucción de índole comparativa de las acciones que Santini Sgaluppi llevó a cabo en Buenos Aires (1892-1893) y Lima (1899-1900); prestaremos especial atención a la actitud que los científicos y médicos de esas ciudades asumieron ante sus acciones y teorías. Este trabajo no solo es una de las pocas reconstrucciones sobre el espiritismo en Perú, sino también un estudio comparativo entre dos países que normalmente son analizados de manera aislada o dentro de circuitos diferentes - Perú en el mundo andino, Argentina en el Atlántico-, especialmente en temas de ciencia y medicina.

Dada la cantidad de emprendimientos llevados a cabo por el conde de Das en el cambio de siglo, no ha de extrañarnos comprobar que sobre su figura se hayan escrito en aquel momento gran cantidad de páginas. Ahora bien, una parte importante de esa literatura está constituida por textos que pretendían denunciar las artimañas y trampas cometidas por el ocultista, o para recordar su largo prontuario judicial. ${ }^{3}$ De hecho, este personaje estuvo envuelto una y mil veces en acusaciones

História da Condenação e Legitimação do Espiritismo (Río de Janeiro: Arquivo Nacional, 1997).

3. El ataque más importante e informado contra Sarak puede hallarse en el libro de Gonzalo Peña y Troncoso, El dosamantismo es la religión científica, en oposición al ocultismo semita que es una liga de internacional anarquismo (México: Editores J. Guerrero y Cía., 1904). Véase también Mario Roso 
de estafa, de ejercicio ilegal de la medicina, de falseamiento de identidad, entre otros "pecados". Su insistente circulación se debió precisamente a ese costado infausto de su reputación. Periódicamente tenía que abandonar su lugar de residencia debido a las causas judiciales o las campañas de desprestigio de las que era víctima. De forma reciente han visto la luz investigaciones (acerca de la historia de la hipnosis o de la cultura esotérica) que han destacado su presencia en Madrid o Buenos Aires a fines del siglo XIX. ${ }^{4}$

Este artículo está dividido en tres partes. La primera de ellas, breve e introductoria, está dedicada a recordar el lugar que le correspondió a los saberes esotéricos, fundamentalmente al espiritismo, en la vida cultural de fines del siglo XIX, así como a trazar algunos lineamientos sobre el carácter regional de ese movimiento. La segunda parte está dedicada a Buenos Aires. Además de bosquejar una somera historización del esoterismo en la ciudad, nos detendremos en el análisis de algunos aspectos de la profesión médica, pues entendemos que esa información será de franca utilidad para comprender las tareas llevadas a cabo allí por Sgaluppi y las respuestas que cosechó. La tercera parte analiza el breve, pero no menos importante, paso de Sarak por Lima y los debates suscitados en dicho país sobre los estudios referidos a los fenómenos de la mente, en especial el rol de las élites intelectuales ante la adopción de conocimiento científico.

\section{Fenómenos psíquicos / espiritistas. Los límites de la ciencia}

El espiritismo y otros fenómenos psíquicos nunca se expandieron más allá de una minoría de la población, sin embargo, estas ideas y prácticas tuvieron un importante rol en la definición de los límites de la ciencia. ${ }^{5}$ Dicho en otros términos, la significación de esas tradiciones esotéricas no debe ser medida por el número de miembros efectivos de distintos agrupamientos, sino más bien por el alcance que sus doctrinas, postulados e interrogantes hallaron en distintos vértices de la cultura científica. Múltiples objetos y fenómenos explotados inicial o mayormente por los acólitos del esoterismo muy pronto fueron reapropiados por representantes de la ciencia académica, y esos préstamos funcionaron muchas veces como catalizadores de conceptualizaciones novedosas. Basta pensar, por ejemplo, en el caso de la telepatía; lo que en un comienzo se presentó como la capacidad prodigiosa de

de Luna, "Para la historia del ocultismo español.El conde Alberto de Das, un émulo de Cagliostro", Hesperia. Revista teosófica y poligráfica 2.3 (1922): 13-16.

4. Andrea Graus, "Hypnosis Lessons by Stage Magnetizers: Medical and Lay Hypnotists in Spain", Notes and Records. The Royal Society Journal of the History of Science 71.1 (2017): 141-156; Quereilhac 141-145.

5. Los debates historiográficos sobre la demarcación científica y los límites entre ciencia y seudociencia son extensos. El trabajo de Thomas Gieryn continúa siendo de lectura imprescindible a ese respecto. Thomas Gieryn, Cultural Boundaries of Science. Credibility on the Line (Chicago: University of Chicago Press, 1999). 
algunos médiums, pasó a constituir el eje de indagaciones científicas realizadas en los ámbitos pulcros de los laboratorios. ${ }^{6}$

Lo mismo cabría afirmar de otras manifestaciones sensitivas o fenómenos de automatismo ligados a la hipnosis, los cuales migraron desde el universo del esoterismo hacia la agenda de trabajo de la neurología o la medicina mental. ${ }^{7}$ Mención especial merece el origen de la psicología científica. El rol esencial que le cupo al positivismo y a la experimentación en el proceso de conformación de la psicología como ciencia ha hecho olvidar, o pasar por alto, que a fines del siglo XIX el estudio de lo "psíquico" o el interés por facultades paranormales formó parte de los variados quehaceres de los promotores de aquella novedosa disciplina científica. ${ }^{8}$ De esta forma, ver la relación entre ciencia y esoterismo solo en términos de confrontación y rechazo supondría mucho más que una simplificación o una parcialidad: significaría un error lamentable. Entre finales del siglo XIX y comienzos de la centuria siguiente fueron reiterados los intercambios, confluencias de vocabularios y trueques de hipótesis o analogías entre la ciencia y esas otras disciplinas esotéricas.

Como plantea ManuelVicuña, aunque se acostumbra considerar al espiritismo como un movimiento alternativo vinculado a lo esotérico, lo cierto es que nunca se postuló como un saber hermético, reservado a un pequeño grupo de iniciados. ${ }^{9}$ Y menos aún como un discurso basado meramente en la fe o en la creencia en lo misterioso o en lo inexplicable. Casi desde sus inicios, el espiritismo moderno se trazó la finalidad de construir un discurso que al mismo tiempo respetara los hábitos esenciales de la ciencia - el valor de las evidencias, el aprecio por el estudio y comprobación de los fenómenos, la puesta en práctica de dispositivos de propaganda basados en la prensa y la divulgación escrita - y cuestionara o impugnara sus fronteras y mecanismos de legitimación. Respecto de esas fronteras, el espiritismo sostuvo una batalla incansable en favor de la existencia legítima de objetos y fuerzas, muchas de estas ligadas a lo espiritual o lo mental, que no eran aceptados por la ciencia como objetos de saber racional (la telepatía, la comunicación con las

6. Roger Luckhurst, The Invention of Telepathy, 1870-1901 (Oxford: Oxford University Press, 2002).

7. De la inmensa literatura histórica sobre la hipnosis durante el siglo XIX, nos han sido de especial utilidad los trabajos que, por un lado, han subrayado el modo en que esas experiencias forzaron a los científicos a revisar sus marcos teóricos y, por otro lado, han insistido en el rol protagónico desempeñado por los no diplomados (ilusionistas, curanderos o charlatanes) en su difusión en ámbitos letrados y populares.Véase Heather Wolffram, The Stepchildren of Science. Psychical Research and Parapsychology in Germany, c.1870-1939 (Amsterdam / New York: Rodopi, 2009); Alison Winter, Mesmerized. Powers of Mind in Victorian Britain (Chicago:The University of Chicago Press, 1998).

8. Régine Plas, "Psychology and Psychical Research in France around the End of the 19th Century", History of the Human Sciences 25.2 (2012): 91-107; Andreas Sommer, "Psychical Research and the Origins of American Psychology: Hugo Münsterberg, William James and Eusapia Palladino", History of the Human Sciences 25.2 (2012): 23-44; Juan José Sosa y Pablo Valderrama-Iturbe, Psychology in Latin America: Historical Reflections and Perspective", International Journal of Psychology 36.6 (2001): 384-394.

9. ManuelVicuña, Voces de ultratumba: historia del espiritismo en Chile (Santiago:Taurus, 2006) 20. 
almas difuntas, la clarividencia, etcétera). Particularmente, se opuso al materialismo más radical, entendido como el que pretendía que la ciencia solo podía ocuparse de elementos, objetos, partículas; por el contrario, el espiritismo reconocía la necesidad de estudiar entidades distintas, ligadas a las energías, las fuerzas y los fluidos. ${ }^{10}$ Igualmente, cuestionaba la validez del monopolio académico del saber sofisticado: la verdad podía provenir de prácticas y actores que nada tenían que ver con las universidades o los laboratorios.

Por tales motivos, las revistas y libros del espiritismo finisecular se convirtieron en una gran caja de resonancia de los adelantos científicos y técnicos. Ello permite explicar el motivo por el cual ese credo pudo resultar tan atractivo para muchos hombres de letras, incluso para algunos con excelente formación científica. En las páginas del esoterismo hallaban una vidriera repleta de noticias sobre los progresos de las ciencias (la física, la medicina, la ingeniería, etcétera), secundada por un discurso que combinaba la defensa de ideales liberales con la prédica de una reforma moral que elogiaba los valores de la filantropía. Por otro lado, esas páginas presentaban a los lectores cultos una noción de ciencia que podía resultar atractiva por varios motivos: con su énfasis en las fuerzas invisibles y las energías, parecía muy en sintonía con teorías recientes en el campo de la física y con innovaciones técnicas como los rayos $\mathrm{X} .^{11}$

Una de las estrategias adoptadas por los esotéricos finiseculares para lograr su expansión y para emular los hábitos de la ciencia moderna estuvo dada por la creación de organizaciones internacionales y congresos que garantizaran la comunicación entre diversas filiales repartidas en el mundo. Un hito clave lo constituyó el Primer Congreso Internacional Espiritista celebrado en Barcelona en 1888, el cual propuso la propagación masiva de la doctrina espiritista a través de la enseñanza y por medio de folletos, obras espiritistas en ediciones populares baratísimas, entre otros. ${ }^{12}$ Como señala Annette Mülberger, en el congreso quedó claro que el espiritismo aspiraba a convertirse en un movimiento de reforma social de tipo progresista y liberal, pues hacía un llamado a los espiritistas de todo el mundo a sumarse a través de sus acciones al cambio social, libertad de consciencia y culto, y a la secularización de diversos aspectos de la sociedad. ${ }^{13}$ En el Congreso destaca la presencia de diversos representantes de América Latina, los cuales mantenían importantes redes transatlánticas con centros espiritistas europeos. En efecto, si bien desde comienzos de la década de 1880 casi todas las grandes ciudades de América Latina contaban con centros y revistas espiritistas, en algunas regiones esas doctrinas se enfrentaron con mayores resistencias y obstáculos, ya sea de parte

10. Richard Noakes, “The 'World of the Infinitely Little': Connecting Physical and Psychical Realities circa 1900", Studies in History and Philosophy of Science 39.3 (2008): 323-334.

11. Simone Natale, "A Cosmology of Invisible Fluids: Wireless, X-Rays, and Psychical Research around 1900", Canadian Journal of Communication 36.2 (2011): 263-275.

12. Primer Congreso Internacional Espiritista (Barcelona: Imprenta de Daniel Cortezo y Ca. Editores, 1888) 198.

13. Mülberger 80-89. 
de sectores católicos o de los gremios científicos locales. Tal y como veremos en lo que sigue, una comparación entre Buenos Aires y Lima puede servir muy bien para comprender tales diferencias.

\section{Un conde en Buenos Aires [1892-1893]}

Tal y como afirmamos al comienzo de este artículo, no solo el intercambio de revistas o la celebración de congresos garantizaron la circulación regional de saberes y teorías. Esa tarea recayó muchas veces en individuos de carne y hueso que mediante sus itinerancias o giras desempeñaron (a veces involuntariamente) esa función. Lo significativo, aunque no excepcional según lo que referiremos en el cierre del texto, de la tarea llevada a cabo por el conde de Das en América Latina estuvo dado no solo por la envergadura de esa empresa (medida en términos de la cantidad de países en que propagó teorías esotéricas y en que fundó sociedades dedicadas a esas doctrinas), sino por el hecho de que él no respondía abiertamente a ninguna organización. No hizo sus viajes como delegado de alguna sociedad internacional, aunque él afirmara repetidamente lo contrario. Movido por sus intereses ocultistas y por un afán irreprimible de lograr notoriedad no respondía a las directivas de ningún centro. Ello no quita, sin embargo, que sus faenas hayan repercutido positivamente en los intereses de movimientos internacionales. Sin ir más lejos, tendremos oportunidad de comprobar que a pesar de que el movimiento teosófico lo haya expulsado de su seno, y haya hecho todo lo posible para que Sgaluppi no se presentara como embajador de ese credo, él fue quien introdujo la teosofía en el Río de la Plata.

Nuestro análisis de los trabajos de Sgaluppi comienza precisamente en Argentina debido a que esa fue su primera escala en su prolongada permanencia en el continente americano. En la ciudad de Buenos Aires vivió desde octubre de 1892 hasta fines de 1893 o comienzos de 1894, y en ese lapso llevó a cabo incontables iniciativas relativas a su especialidad. Antes de emprender el estudio de los indicios de su paso por la ciudad, haremos un breve comentario de su carrera anterior y recuperaremos los datos esenciales sobre el contexto porteño en que efectuó sus iniciativas.

No contamos con una biografía confiable del conde. Sabemos que su verdadero nombre era Alberto Santini Sgaluppi, que era de origen italiano y que habría nacido en el año 1855. Todo cuanto él alegó de sí mismo (que había nacido en la India, que había obtenido título médico en París, que era conde, etcétera) fue puesto en duda por sus detractores, y probablemente con razón. ${ }^{14}$ Las fuentes menos inciertas son las infinitas crónicas periodísticas que a lo largo de los años fueron documentando sus trabajos en distintas ciudades del mundo. Así, los indicios más tempranos sobre sus trabajos se remontan a abril de 1887 , cuando bajo el

14. El conde bosquejó en múltiples entrevistas a periódicos su presunta biografia. La versión más extensa está contenida seguramente en el folleto, probablemente autobiográfico, publicado en Montevideo en 1906; véase El Conde de Das (Albert de Sarâk) (Montevideo: Imprenta Rural, 1906). 
nombre de "Dr. Alberto Daas" dictó en Cataluña conferencias y ofreció demostraciones de hipnotismo ante el público general y ante audiencias conformadas por médicos, por ejemplo, en la Facultad de Medicina de Barcelona. ${ }^{15} \mathrm{Su}$ principal notoriedad llegaría a partir de diciembre de ese año, cuando comenzó a mostrar sus poderes y conocimientos ante el público de Madrid. En la capital española logró tal nivel de reputación que incluso la antigua reina regente lo invitó a realizar una demostración de hipnotismo y telepatía en los salones de la familia real, sesión que tuvo lugar el 13 de enero de 1888 y que fue objeto de positivas crónicas en la prensa general. ${ }^{16}$ De todas maneras, Sgaluppi no se dedicó solamente a divertir a los convidados a esas veladas en salones de la élite. Efectuó otras tareas que parecían reforzar su pertenencia a la disciplina científica, y que parecían encaminadas a enfatizar el carácter respetable de sus iniciativas. Por un lado, había comenzado a publicar una revista semanal titulada La Hipnoterapia, que contenía textos propios y traducciones de trabajos de médicos franceses. ${ }^{17}$ Por otro lado, el 6 de febrero de 1888 dictó una conferencia en el Círculo Militar, siguiendo un programa elaborado con riguroso vocabulario galénico. ${ }^{18}$

En diciembre de 1890 el conde fue encarcelado como consecuencia de denuncias de acreedores a quienes debía dinero. Junto con la noticia de su detención, los diarios comunicaron su verdadera identidad y denunciaron que carecía de título médico o de condición nobiliaria. ${ }^{19}$ Poco después habría regresado a Barcelona aproximándose a la filial local de la teosofia, lo cual no resulta sorprendente si consideramos que en sus textos existía una notoria familiaridad con el vocabulario esotérico. De todas formas, tampoco tuvo suerte en esa nueva empresa. Hacia mediados de 1892 los teósofos de Barcelona lo expulsaron de la Sociedad debido a su mal comportamiento, situación que seguramente estuvo relacionada con nuevos episodios de estafa. ${ }^{20}$

El polémico conde se embarcó hacia Buenos Aires en compañía de su esposa, Antonia Martínez de Royo, la condesa de Das. No sabemos qué planes tenían para su futuro, ni por qué motivo eligieron ese nuevo destino. Tampoco sabemos si su intención original era establecer residencia definitiva en Argentina. Con ese escape se inició un prolongado periplo por muchos países del continente americano, y gracias a esa incansable trashumancia el conde se convertiría en uno de los

15. La Dinastía (Barcelona) 16 de abril de 1887: 2. Para un análisis del paso del conde de Das por España, véase Mauro Vallejo, El Conde de Das en Buenos Aires, 1892-1893. Hipnosis, teosofía y curanderismo detrás del Instituto Psicológico Argentino (Buenos Aires: Biblos, 2017).

16. El Siglo Futuro (Madrid) 17 de enero de 1888: 2.

17. El primer número habría aparecido el 5 de febrero de 1888. La Iberia (Madrid) 11 de febrero de 1888: 2. No hemos podido dar con ningún ejemplar de esa revista, y no aparece citada en la literatura especializada.

18. "Academias, ateneos y sociedades", La Época (Madrid) 5 de febrero de 1888: 2.

19. Véase La Época (Madrid) 26 de diciembre de 1890: 4; "El Conde preso", El Heraldo de Madrid (Madrid) 26 de diciembre de 1890: 1.

20. "Advertencia", Estudios Teosóficos (Barcelona) 7 de septiembre de 1892: 341. 
actores esenciales de la difusión regional del esoterismo. La pareja de "condes"llegó a Buenos Aires hacia fines de octubre de 1892. Nuestro especialista en hipnosis permaneció en la ciudad poco más de un año y durante ese lapso llevó adelante múltiples iniciativas, algunas de las cuales le valieron el rechazo de sectores ligados a la medicina o la Iglesia católica. Pero en su paso por Buenos Aires también supo conquistar la amistad o el aprecio de individuos bien posicionados en el mundo letrado tales como espiritistas, científicos de renombre e incluso algunos egresados de la Facultad de Medicina. El estudio de sus tareas en el Río de la Plata habrá de servirnos como mirador de algunos dinamismos fundamentales como la popularidad de los cientificismos heterodoxos en la cultura letrada o las tensiones de un mercado de la salud marcado por la competencia entre los profesionales.

Al igual que en España, la estrategia inicial de Sgaluppi fue presentarse en sociedad como médico y como investigador de fenómenos mentales. En un texto de bienvenida publicado por el prestigioso diario La Nación se informaba que, además de poseer título en medicina y de ser conde, el recién llegado era "director de la Revista Científica de España". ${ }^{21}$ Debido a que ostentaba semejantes credenciales, los principales periódicos de la ciudad siguieron con mucha atención los primeros pasos del especialista en hipnosis y publicaron detalladas reseñas de sus conferencias y demostraciones. Deseoso de ganarse rápidamente al público local, Sgaluppi exhibió sus pericias muy pocos días después de su desembarco. En la noche del 31 de octubre de 1892 tuvo lugar una primera sesión de hipnotismo en el Hotel de Roma en la que se prometían, tal y como la prensa se encargó de promocionar, demostraciones de catalepsia y éxtasis. ${ }^{22} \mathrm{Al}$ día siguiente casi todos los diarios de Buenos Aires incluyeron reseñas entusiastas sobre esa primera sesión y resaltaron la presencia de personas distinguidas (incluyendo médicos y abogados) entre el público. ${ }^{23} \mathrm{Al}$ igual que en sus ulteriores iniciativas en la ciudad, Sgaluppi había trabajado con el auxilio de su esposa. Ella era en verdad el atractivo principal de las veladas, pues era quien en estado hipnótico era capaz de mostrar capacidades sorprendentes de telepatía y adivinación.

Cabe notar que unos pocos diarios hicieron saber sus reservas respecto de las labores del hipnotizador. La crítica principal no pasaba por poner en duda la buena fe del extranjero ni en cuestionar la realidad de los fenómenos producidos, por el contrario, lo que despertaba suspicacias o enojos era que ese tipo de exhibiciones tuvieran lugar en ambientes profanos y no en aulas de medicina o en anfiteatros de la universidad. ${ }^{24}$ Esa queja no era nueva, y tampoco lo eran las maravillas exhibidas por Sgaluppi. No era la primera vez que los porteños tenían ocasión de observar con sus propios ojos los milagros del hipnotismo, la clarividencia o la telepatía, pues en los años previos muchos especialistas en tales asuntos habían brindado sus

21. “El Dr. A. de Martínez”, La Nación (Buenos Aires) 29 de octubre de 1892: 3.

22. "Conferencia pública sobre psiquiatría”, La Prensa (Buenos Aires) 30 de octubre de 1892: 3.

23. "Hipnología”, El Correo Español (Buenos Aires) 1 de noviembre de 1892: 2.

24. "La conferencia del Dr. Martínez de Das", La Nación (Buenos Aires) 1 de noviembre de 1892: 1. 
espectáculos en teatros y salones de la ciudad. ${ }^{25}$ Tampoco era la primera vez que algunas voces se alzaban para condenar la explotación teatral del hipnotismo. Desde finales de la década de 1880, diversos periódicos habían explicitado esa condena cada vez que un hipnotizador de teatro visitaba la ciudad; más aún, en diciembre de 1890 el Departamento Nacional de Higiene había dictado una resolución que prohibía expresamente ese uso teatral del hipnotismo. ${ }^{26}$

Lo que quizá era novedoso en el accionar del conde era el modo en que parecía combinar abiertamente tradiciones que habían permanecido distantes entre sí en la ciudad. Hasta entonces, nadie había sugerido una mixtura tan clara entre medicina y ocultismo o esoterismo. En las crónicas sobre la primera exhibición ese parentesco era evidente, y el mismo se profundizará con el correr de los días. En efecto, casi de inmediato Sgaluppi publicó un texto teórico en la principal revista del espiritismo porteño en el cual abundaban las referencias a conceptos esotéricos (como el "Od" o las "fuerzas radiantes"). ${ }^{27}$ Esa primera colaboración marcó el inicio de una férrea asociación entre el hipnotizador y los miembros de la sociedad kardeciana Constancia. Ese señalamiento nos da pie para bosquejar, al menos de modo sucinto, qué características había tenido el esoterismo en Buenos Aires en los años previos, lo que nos colocará en mejores condiciones para comprender el terreno en que Sgaluppi efectuó sus emprendimientos.

De modo general, podemos afirmar que el espiritismo llegó a la ciudad de Buenos Aires a fines de la década de 1860, sobre todo, gracias al arribo de inmigrantes españoles que profesaban esa creencia. ${ }^{28}$ En los primeros años el movimiento fue marginal, pero esa situación comenzó a modificarse una década más tarde, principalmente, con la fundación de Constancia y con la emergencia de la revista homónima que comenzó a editarse en noviembre de 1877. Gracias a la labor de difusión garantizada por ese órgano de prensa, y gracias sobre todo al empuje que supo darle al movimiento Cosme Mariño a partir de 1883, el espiritismo vivió hasta fines de siglo una suerte de "edad de oro". ${ }^{29}$ Durante estos "años dorados" Constancia produjo una cuantiosa literatura de propaganda, las iniciativas de los kardecianos fueron tomadas cada vez más en serio por diversos actores del mundo cultural y las filas del espiritismo estuvieron conformadas por algunos representantes destacados del mundo letrado. No solamente los periódicos generales anunciaban la aparición de cada número de la revista o la celebración de actividades, sino que los espiritistas porteños se transformaron en partícipes activos de debates públicos de gran resonancia (celebrados en la década de 1880 en los

25. Mauro Fernández, Historia de la magia y el ilusionismo en la Argentina (Buenos Aires: [s.e.], 1996).

26. La resolución fue publicada en los Anales del Departamento Nacional de Higiene 1.5 (1891): 303-304.

27. A. M. de Das, "Salve", Constancia 15.281 (1892): 291.

28. Quereilhac 60.

29. Sobre la importancia de Mariño para el espiritismo argentino y latinoamericano, véase Marcelo Garabedian, "Cosme Mariño y el periodismo del siglo XIX", Memorias de un hombre mediocre. Cosme Mariño (Buenos Aires: Dunken, 2010) 13-22. 
principales teatros de la ciudad, y en los que algunos científicos de renombre cuestionaron los fundamentos del espiritismo).

Ahora bien, para el momento en que Sgaluppi llega a la ciudad, el kardecismo porteño seguía gozando de esa buena salud, sin embargo, la época dorada era ya cosa del pasado. Los diarios prestaban cada vez menos atención a sus iniciativas y eran cada vez más frecuentes los indicadores de una actitud de desconfianza. Sin ir más lejos, apenas unas semanas antes de que Sgaluppi llegara a Buenos Aires el espiritismo había sido víctima de una agresiva campaña de desprestigio por parte de esos órganos de prensa. El desencadenante había sido el intento de asesinato sufrido por Cosme Mariño en la noche del 5 de octubre de 1892. Según los diarios se encargaron de repetir una y otra vez, la atacante, Filomena Dolores de González, había frecuentado las reuniones de Constancia en los días previos, y en su gesto homicida los periodistas de Buenos Aires quisieron ver la confirmación de que la adhesión al espiritismo era causa de enajenación mental. ${ }^{30}$

El incidente referido al ataque a Mariño sirve, entonces, para captar la representación que por ese entonces podía tener del espiritismo un sector del mundo letrado, así como para entender el fervor con que los miembros de Constancia defenderán las iniciativas de Sgaluppi. De hecho, en el instante en que los diarios reflotaban la vieja teoría según la cual la adhesión al esoterismo era causa de locura, un presunto médico extranjero, quien, además, ostentaba títulos nobiliarios, manifestaba su interés por la doctrina de Allan Kardec. ${ }^{31}$ Los integrantes de Constancia no podían dejar pasar la oportunidad y es por ello que hicieron todo lo posible por divulgar las acciones del conde.

La cercanía entre Sgaluppi y los kardecianos quedó en evidencia sobre todo con la fundación del Instituto Psicológico Argentino a mediados de diciembre de ese año. En efecto, en puestos claves del nuevo organismo figuraban nombres destacados del espiritismo porteño (tanto Cosme Mariño como Felipe Senillosa aparecían como vocales del Consejo Directivo). ${ }^{32}$ Con esa fundación quedó de manifiesto, asimismo, que el conde seguía confiando en la posibilidad de hacer confluir discurso esotérico y medicina clínica. En efecto, uno de los objetivos del Instituto era habilitar una clínica de enfermedades nerviosas, que estaría bajo la dirección

30. "Precauciones contra el espiritismo", El Diario (Buenos Aires) 7 de octubre de 1892: 2.

31. Allan Kardec fue el pseudónimo utilizado en sus obras por el pedagogo francés Hippolyte Léon Denizard Rivail (1804-1869). A través de su libro El libro de los espíritus (1857) otorgó al movimiento espiritista una doctrina compleja y razonada, presentada en un lenguaje racional y en un estilo didáctico. Su teoría se basaba en dos postulados mayores: primero, la existencia de un mundo espiritual habitado por las almas de los difuntos, que puede entrar en comunicación con los hombres vivientes; segundo, la operatoria de una ley progresiva, merced a la cual las sucesivas reencarnaciones permitirían un perfeccionamiento o evolución moral. Si bien su interpretación conoció una amplia y rápida difusión en Occidente, el espiritismo terminó por dar la espalda al anhelo de Kardec de que el movimiento no acabara enfrentado a la Iglesia católica; al respecto véase Brady Brower, Unruly Spirits. The Science of Psychic Phenomena in Modern France (Urbana: University of Illinois Press, 2010).

32. Estatutos Generales. Reglamento interior. Instituto Psicológico Argentino (Buenos Aires: Roma, 1892). 
del "Dr. Alberto Martínez de Das". Algunos médicos figuraban, por supuesto, en el organigrama del Instituto, sin embargo, esa presencia no puede tomarnos por sorpresa.Ya durante su paso por España, Sgaluppi había sabido atraer la atención de los doctores, quienes habían asistido a los cursos de hipnotismo dictados por él. ${ }^{33}$ Los mismos factores que sirven para explicar su éxito español pueden ser recuperados para entender la franqueza con que diplomados porteños se enrolaron en el trabajo del Instituto. De la misma manera, aquí existía un lamentable contraste entre el interés que generaba la hipnosis como herramienta terapéutica y la escasez de mecanismos o dispositivos académicos capaces de introducir a los médicos en el nuevo arte. ${ }^{34}$ Sgaluppi había llegado a Buenos Aires con credenciales envidiables y es natural que algunos profesionales se hayan sentido atraídos por un emprendimiento clínico y pedagógico que prometía introducirlos en tópicos de avanzada.

La extraña mezcla entre esoterismo y medicina no podía pasar desapercibida para las miradas más recelosas; por ejemplo, algunos diarios denunciaron ese parentesco, equiparando el Instituto directamente con un nuevo centro kardeciano. ${ }^{35}$ Sin demora, las autoridades sanitarias reaccionaron y solicitaron a la policía que prohibiera la realización de conferencias públicas de hipnosis. ${ }^{36}$ Los miembros del Departamento Nacional de Higiene aún no ponían en duda el título médico de Sgaluppi. Lo que veían como peligroso era la presencia de espiritistas y no médicos en el organigrama de una institución que pretendía ofrecer auxilios terapéuticos; por otro lado, habían seguido con atención las demostraciones públicas anteriores del conde y no querían que la normativa sobre el hipnotismo público volviese a ser infringida. Por último, Sgaluppi no había aún revalidado su presunto título de doctor y, por ende, no estaba habilitado para ejercer el arte de curar en el país.

Por un tiempo el Instituto siguió funcionando normalmente, y el conde siguió ofreciendo allí sus conferencias y demostraciones. ${ }^{37}$ Sin embargo, una nueva voz apareció en la contienda: en una joven revista del sector católico, Artes y Letras, se publicaron tres artículos en contra del conde. ${ }^{38}$ En esas páginas se respaldaba la medida del Departamento de Higiene y se alertaba sobre los peligros sanitarios de las exhibiciones de hipnotismo efectuadas por Sgaluppi. A pesar de que los espiritistas respondieron extensamente a los argumentos esgrimidos por la publicación

33. Graus, "Hypnosis Lessons" 150.

34. Mauro Vallejo, "Buenos Aires mesmérica. Hipnosis y magnetismo en la cultura y la ciencia de la capital argentina (1870-1900)", Revista Iberoamericana 14.56 (2014): 7-26.

35. "El consejo de higiene y la psiquiatría”, La Tribuna (Buenos Aires) 17 de diciembre de 1892: 2.

36. "Las conferencias psicológicas", La Prensa (Buenos Aires) 17 de diciembre de 1892: 3.

37. "Instituto Psicológico Argentino", La Prensa (Buenos Aires) 10 de enero de 1893: 2.

38. José María Cabezón, "Hipnotismo y sugestión. ¿Pueden emplearse como medio curativo o como agentes de moral?", Artes y Letras (Buenos Aires) 4 de diciembre de 1892: 13-15; José María Cabezón, "Espiritismo y locura”, Artes y Letras (Buenos Aires) 1 de enero de 1892: 72 75; José María Cabezón, "Hipnotismo, sugestión y crimen", Artes y Letras (Buenos Aires) 15 de enero de 1893: 102-104. 
católica, todo indica que hacia comienzos de febrero de 1893 el Instituto tuvo que cerrar sus puertas. ${ }^{39}$

Ese fracaso no desanimó a Sgaluppi, ni lo desalentó para continuar sus labores en el terreno de la salud o la medicina. En efecto, en la segunda mitad de 1893 el hipnotizador llevó adelante dos nuevas iniciativas. Por un lado, en junio de ese año fundó en colaboración de su esposa la sociedad Luz, primera filial de la teosofía en el país. Pronto las máximas autoridades del movimiento teosófico se percataron de que el fundador era el mismo sujeto que ya había sido expulsado de las filiales españolas y decretaron su reexpulsión inmediata. ${ }^{40} \mathrm{El}$ conde, experto en escapes apresurados, hizo sus valijas y comenzó su largo viaje por el continente. Su esposa, Antonia Martínez Royo, decidió quedarse en la ciudad. Se hizo cargo de la inmediata refundación de la sociedad teosófica Luz y dirigió sus actividades con el auxilio de Alejandro Sorondo hasta su muerte (en 1897).

Por otro lado, la segunda iniciativa que mantuvo ocupado a Sgaluppi hasta su huida de Buenos Aires tuvo que ver con la medicina. Más o menos a partir de julio de 1893 comenzó a realizar sus exhibiciones y conferencias de hipnotismo en colaboración de un médico local, Osvaldo García Piñeiro. Es probable que optara por asociarse a un médico diplomado como una forma de evitar las persecuciones de las autoridades sanitarias. En septiembre de ese año tuvo lugar la última de las actividades efectuadas entre ambos. ${ }^{41}$

En síntesis, el análisis de las faenas bonaerenses del conde de Das sirve, en primera instancia, para arrojar evidencias complementarias acerca de la buena acogida que las iniciativas e ideas esotéricas podían hallar en algunos sectores del mundo letrado; proceso que en los últimos años ha recibido una franca atención por parte de los estudiosos. En segunda instancia, y en sentido inverso, ilumina el tipo de resistencias que esos credos heterodoxos podían despertar entre las autoridades sanitarias y los representantes de la Iglesia. En tercera instancia, los documentos explorados hasta aquí ponen de relieve la complejidad y variedad del mundo médico y del mercado de la salud a fines de siglo. A un costado de los higienistas oficiales, deseosos de hacer cumplir las normativas sobre hipnotismo teatral o ejercicio legal de la medicina, existieron muchos doctores que sin titubear se asociaron a un hipnotizador estrafalario que en sus discursos combinaba neurología y espiritismo. Hubo doctores que, incluso después de divulgadas las medidas represivas contra el conde (y falso médico), no tuvieron inconvenientes en prestar su firma para que el extranjero pudiera continuar con sus empresas. Creemos que el examen de este tipo de casos debería invitar a revisar el perfil de la profesión médica delineado

39. Ovidio Rebaudi, "El Instituto Psicológico Argentino y el Dr. Gamaliel”, Constancia (Buenos Aires) 29 de enero de 1893: 34-35.

40. "Reexpulsión de D. Alberto de Das (Conde de Das) de la Sociedad Teosófica", Sophia. Revista Teosófica (Madrid) 1 de octubre de 1893:242-244.

41. En la pequeña nota de La Prensa, que anunciaba aquella sesión de septiembre, se informa que el nuevo emprendimiento de Das y García Piñero se llamaba el "Instituto médico hipno-electroterápico"; "Hipno-electro-terápico", La Prensa (Buenos Aires) 2 de septiembre de 1893: 2. 
generalmente en la literatura histórica y a reconocer que muchos doctores del período habitaban una zona gris en la que los postulados del positivismo higienista no regían demasiado, y en donde las identidades del médico, del sanador y del aventurero podían confundirse entre sí.

\section{Un espiritista de folletín. El conde de Sarak en Lima ${ }^{42}$}

Tras su huida de Buenos Aires y luego de una larga estadía en Montevideo, el espiritista se asentó en Chile entre abril y septiembre de 1899. Por ese entonces el periódico El Comercio de Lima, el más importante a nivel nacional, informaba del arribo a la capital peruana del "doctor Alberto de Sarak, conde de Das, profesor de psicoterápica de Montevideo”, dejaba atrás el apellido Sgaluppi y la identidad que había forjado en Argentina. ${ }^{43}$ Según el periódico, Sarak permanecería en la ciudad solo unas pocas semanas, tiempo suficiente para que los deshielos abrieran el paso de la cordillera de Chile y así regresar a Montevideo vía Buenos Aires, donde dirigía una clínica psicoterápica. Desconocemos si el conde buscaba instalarse en Lima, pero lo cierto es que durante los casi cinco meses que residió en la capital peruana no dejó indiferente a la élite médica y científica curiosa de aprender de los fenómenos psíquicos, siendo Carlos Paz Soldán uno de los principales defensores de las teorías y prácticas de la mente que Alberto de Sarak desarrolló en Perú.

Antes de abordar el paso de Sarak por Lima, es necesario explicar brevemente el estado de los estudios espiritistas en Perú donde tenían una presencia mucho menor en comparación con otros países de América Latina.A diferencia de Argentina, donde diversos fenómenos psíquicos / esotéricos se difundían en publicaciones y grupos de estudio, en Perú el único espacio exclusivo donde se publicaron dichas temáticas era la revista El Sol dirigida por Carlos Paz Soldán, hombre de ciencia y miembro de una de las familias más importantes de la aristocracia limeña. ${ }^{44}$ En la década de 1880 Paz Soldán había iniciado el estudio y práctica del espiritismo en un país que, como él mismo reconocía, apenas sabía algo sobre esta disciplina. ${ }^{45}$ Pese a que en ese momento en otras ciudades del Cono Sur ya existía un grupo importante de estudiosos del espiritismo, en Lima el acercamiento de Carlos Paz Soldán a esta doctrina fue catalogado como un problema psiquiátrico. Como el mismo Paz Soldán explicaba, el diagnóstico de "locura espiritista" por parte de los

42. El título refiere a un artículo publicado por el intelectual peruano José Carlos Mariátegui sobre el Conde de Sarak, el cual es uno de los pocos que advirtió sobre la presencia de dicho espiritista en el país, aunque presenta algunas imprecisiones en cuanto a fechas. José Carlos Mariátegui, "Un aventurero de folletín", Escritos juveniles, t. 2, comp. Alberto Tauro (Lima: Biblioteca Amauta, 1915) 67-72.

43. "Profesor de Psicoterapia", El Comercio (Lima) 28 de septiembre de 1899: s.f.

44. Augusto Ruiz, Psiquiatras y locos. Entre la modernización contra los Andes y el nuevo proyecto de modernidad. Perú: 1850-1930 (Lima: Instituto Pasado \& Presente, 1994) 57; Arturo Orbegoso, "Espiritismo, locura e intelectuales del 900", Revista de Psicología de Trujillo 14.1 (2012): 95-105.

45. Carlos Paz Soldán, Estudios espiritistas y la vida de loco (Lima: Imprenta Liberal de F. Masias y Ca.,1886) 184. 
médicos radicaba en la incomprensión de ciertos fenómenos nuevos de la ciencia en el Perú, una situación que, según él, no hubiese sucedido en Europa "por que allí el ser humano está a un alto grado de desarrollo". " Por su "locura espiritista" en 1885 fue encerrado forzosamente más de tres meses en el asilo de Orates, una condición que según el médico y director de dicha institución, doctor Casimiro Ulloa, se producía por la exaltación mental causada por el espiritismo, el cual no era más que una "nueva superstición” que daba origen a un sin número de imposturas y fraudes, y "a su vez de un gran fanatismo por parte de sus seguidores que se han visto atrapados en dicha superstición". ${ }^{47}$

Sin embargo, no toda la élite intelectual compartió la perspectiva de Ulloa sobre el espiritismo y los fenómenos psíquicos. La Gran Logia Masónica peruana mostró gran interés por la ciencia y por la psicología, y es posible que mantuviera una actitud de tolerancia hacia el espiritismo. ${ }^{48}$ La Revista Masónica del Perú dio cabida a artículos referidos a las experiencias médicas del hipnotismo, así como los problemas que este conllevaba. ${ }^{49}$ De esta forma, no es de extrañar la participación de varios masones en los espectáculos que Sarak organizara en la capital peruana. Posterior a su paso por el manicomio, Paz Soldán renovó su compromiso con estos fenómenos y fundó y dirigió El Sol, la única revista de su tipo hasta la llegada de Sarak al país.

Pese a que los espiritistas tuvieron que hacer frente a varias adversidades para difundir sus postulados, los limeños estuvieron maravillados con la llegada del conde de Sarak en 1899, quien se presentó en la ciudad como médico y miembro de diversas instituciones científicas en Europa y América ${ }^{50}$ La validez de sus supuestos títulos médicos le había permitido incorporarse a la Facultad de Medicina de Lima, información que fue negada por dicha institución una vez que su farsa quedara al descubierto en abril de $1900 .{ }^{51}$ Uno de los primeros eventos en la ciudad, y que le permitió obtener cierta legitimidad en los círculos científicos, fue una conferencia que brindó en la Academia Nacional de Medicina, una prestigiosa organización que agrupaba a los más ilustres médicos del país. Según consta en su órgano de difusión, La Crónica Médica, la Academia "no podía cerrar sus puertas a quien premunido con títulos científicos debidamente legalizados pretendía poner de manifiesto verdades para nosotros ignoradas". Como se describe en la revista, ante un público numeroso entre los que se encontraban académicos, varios médicos y muchos estudiantes excitados por la curiosidad,

46. Paz Soldán 12 .

47. Casimiro Ulloa, "La locura espiritista”, El Ateneo de Lima (Lima) 22 de julio de 1887: 321-325.

48. Magdalena Chocano, "Lima masónica: las logias simbólicas y su progreso en el medio urbano a fines del siglo XIX”, Revista de Indias 70.249 (2010): 429.

49. Modesto Santiesteban, "Hipnotismo", La Revista Masónica del Perú (Lima) 1 abril de 1890: 86-87; Camilo Flanmarion, "La personalidad humana. Los peligros del hipnotismo", La Revista Masónica del Perú (Lima) 1 mayo de 1890:110-112.

50. Son escasas las menciones del paso de Sarak por Perú, véase Mariátegui.

51. "Profesor de Psicoterapia”, El Comercio (Lima) 28 de septiembre de 1899: s.f. 
Sarak había realizado algunos fenómenos de sugestión "con más o menos talento práctico" presentó teorías oscuras, muchas de ellas en contradicción de la verdad científica. ${ }^{52}$ Los medios de prensa informaron en detalle su presentación, la cual estuvo centrada en los fenómenos psíquicos mentales, experiencias que según El Comercio "fueron ejecutados por el doctor Sarak con aplauso general, siendo opinión unánime que los trabajos efectuarlos, valiosos en él, por las teorías científicas que en ellos se han desarrollado necesitan un estudio mediante y concienzudo". ${ }^{53}$

En las semanas posteriores a su arribo, la labor de Alberto de Sarak se intensificaría en la capital peruana. Como una estrategia para posicionarse públicamente como especialista en fenómenos mentales comenzó a publicar de manera regular en El Comercio artículos sobre psiquiatría y fenómenos de la mente. En una carta enviada al periódico en octubre de 1899 sostenía la importancia del movimiento de lo que llamaba ciencia psicológica, un campo que según Sarak era mirado con escepticismo, pero que se iba abriendo paso entre los hombres de ciencia. ${ }^{54}$ Junto con la publicación de dichos textos, Sarak comenzó a dictar cursos de "psiquiatría", una rama de la medicina que aún estaba definiéndose en Perú. ${ }^{55}$ Sarak prometía enseñar a los presentes las más modernas teorías científicas sobre telepatía, visión astral, ciencias ocultas, transmisión del pensamiento, en las cuales junto al estudio teórico el "médico" realizaba demostraciones prácticas. ${ }^{56}$

En las siguientes sesiones el número de asistentes aumentaría captando la atención principalmente del público femenino. Otro grupo que se vio interesado en los "actos científicos" de Sarak fue el gremio médico, y pese a que la Academia de Medicina planteaba que varios de sus postulados iban en contra del quehacer científico, este grupo fue uno de los más entusiastas asistentes a sus cursos y presentaciones públicas. Según informaba El Comercio, a la primera lección habían asistido más de 24 personas, entre los que se destacaban los doctores Belisario Piedra, Juan Arturo Ego Aguirre y Jorge Figueroa, miembros ilustres de la Facultad de Medicina de Lima. ${ }^{57}$ Es interesante notar que fueron estos mismos doctores quienes en el mes de noviembre salieron en defensa de Sarak y de sus cursos, al expresar públicamente que luego de haber asistido asiduamente a estos daban fe de que "todos los fenómenos presentados por dicho caballero son completamente auténticos, y no dan lugar a duda", ${ }^{58}$

52. "La conferencia del Dr. Sarak", La Crónica Médica (Lima) 15 de octubre de 1899: 357.

53. "Conferencia en la Academia de Medicina”, El Comercio (Lima) 1 de octubre de 1899.

54. "Conferencia en la Academia de Medicina", El Comercio (Lima) 1 de octubre de 1899.

55. Sus lecciones sobre psicología y "ciencias esotéricas" fueron publicadas en formato de libro ese mismo año.Véase Alberto de Sarak, Psicología moderna y ciencias ocultas (Lima: Imprenta Liberal, 1899).

56. "Aviso de preferencia. El Dr.A. de Sarak", El Comercio (Lima) 2 de diciembre de 1899:s.f.;"Cursos de Psiquiatría por el doctor A. de Sarak", El Comercio (Lima) 13 de octubre de 1899: s.f.

57. "Primera lección del Doctor Sarak", El Comercio (Lima) 15 de octubre de 1899: s.f.

58. "Intereses generales. La psiquiatría del doctor Sarak", El Comercio (Lima) 13 de noviembre de 1899: s.f. 
Similar a su forma de operar en Argentina y Chile, a un mes de su arribo fundó el Centro Esotérico Porvenir bajo su inmediata dirección. ${ }^{59}$ Según narra Christian Dam, ex-gran masón y librepensador, a finales de octubre el llamado conde había invitado a ocho ilustres caballeros a su casa en donde celebraron una sesión con el objeto de formar el Centro Esotérico. En esa ocasión, Sarak se adjudicó el cargo de delegado general sudamericano del Supremo Consejo del Thibet y les exigió a los flamantes miembros la suma de 100 soles, dinero que nadie sabía dónde había ido a parar. Si bien Christian Dam solo presentó las iniciales de quienes formarían parte del Centro, es posible deducir la presencia de importantes miembros de la élite peruana como Carlos Paz Soldán, quien actuó como vicepresidente del Centro, y el gran maestre de la masonería peruana, nada menos que el médico Juan Arturo Ego Aguirre, quien por ese entonces había firmado junto a otros médicos una carta de apoyo a Sarak. ${ }^{60}$ Una de las actividades del Centro fue la publicación de la revista El Loto, de la que se eligió a Paz Soldán como su redactor en jefe y director.

Las presentaciones de Sarak generaron controversia en la élite limeña y dividieron a los asistentes entre quienes lo defendían y lo criticaban. Las primeras reacciones provinieron de los sectores católicos conservadores de la ciudad, quienes criticaban las presentaciones de las "ciencias ocultas", a lo cual Sarak debió salir a responder públicamente que uno de los deberes de las personas que desarrollaban el esoterismo era respetar todos los cultos y creencias, y que la ciencia que él desarrollaba no era contraria a ninguna religión. ${ }^{61}$ Fue el periodista Fernández Pasalagua el primero en poner públicamente en duda sus teorías. En una carta enviada a El Comercio en noviembre de 1899, Pasalagua expresaba que:

El doctor Sarak, abusando de la benevolencia que esta hospitalaria tierra peruana ha querido sorprender a esta sociedad con experiencias, que presentadas bajo la forma científica no encierran en su fondo más que burdos artificios, toscamente encubiertos las más de las veces [...] El doctor Sarak no es médium ni faquir ni nada de eso; se ha demostrado claramente que es un médico, buen vividor e igual a los demás que se rodea de una especie de aureola de misterio para adquirir una notoriedad efimera. ${ }^{62}$

Pasalagua basaba su crítica en el alto costo de las presentaciones y en la poca disponibilidad de Sarak para aceptar la crítica, a pesar de llamarse "científico". El espectáculo estaba reservado solo para aquellos que previamente habían cancelado la tarifa de 20 soles, y a pesar de la insistencia del periodista para que Sarak repitiera algunos de los fenómenos, este no estaba dispuesto a discutir los fenómenos psíquicos que presentaba. Llama la atención que no será Sarak, sino los asistentes

59. Mariátegui 60

60. "El Centro Esotérico Porvenir del Perú y la gran farsa del doctor Sarak Conde de Das”, El Librepensamiento (Lima) 7 de abril de 1900: 2.

61. "Intereses generales. Psicología y cristianismo", El Comercio (Lima) 14 de octubre de 1899: s.f. Sobre el conflicto entre espiritismo y catolicismo, véase Mülberger 69-80.

62. "La psiquiatría del doctor Sarak”, El Comercio (Lima) 10 de noviembre de 1899: s.f. 
al espectáculo quienes defiendan los cursos de psicología. Entre ellos se encontraba Carlos Paz Soldán, quien no solo dio fe de los fenómenos presentados, sino que negó completamente que se tratara de una estafa económica por parte de Sarak. Según Paz Soldán, "el desinterés del doctor Sarak es altamente loable por cuanto, en su totalidad el producto de la matricula apenas si alcanza a cubrir la impresión de las lecciones como a todos nos consta". ${ }^{63}$

Los postulados de Sarak y sus estafas quedarían de manifiesto en los meses siguientes, gracias a la labor del Christian Dam y El Librepensamiento. Por cuatro meses, el periódico publicó artículos contra Sarak en los que refutaba las doctrinas y credenciales que el llamado conde decía ostentar. Si bien este respondió a la crítica contra el liberalismo apuntando sus dardos contra Dam, a inicios de abril decidió repentinamente dejar el país. En una carta publicada en el diario El Comercio titulada "A mis amigos y al público", Sarak informaba de su abrupta partida por motivos de salud de su hijo, lo que lo obligaba a dejar la ciudad por un par de semanas. En la carta aprovechaba para expresar su gratitud a las personas que lo habían honrado en la capital peruana con su amistad, y en especial al diario El Comercio por "la benévola acogida que ha dispensado a un humilde obrero de la ciencia". ${ }^{64}$ No obstante, la partida respondía a otras razones, como lo informaría Christian Dam en El Librepensamiento y en El Sol, este último dirigido por Carlos Paz Soldán.

La circulación de noticias sobre Alberto de Sarak provenientes de España, Argentina y Chile jugó un rol clave en la apresurada partida de este de Perú. Según Paz Soldán, en febrero de ese año recibió una carta desde Chile, en la que se informaba que Sarak había realizado presentaciones en Barcelona y Madrid, ciudades donde había sido condenado por fraude. También se enteró de que la Facultad de Medicina de Lima no lo había reconocido oficialmente como médico, y que varios de los artículos publicados en El Comercio firmados como propios eran, principalmente, plagios de otras publicaciones teosóficas. Al verse descubierto, Sarak había decidido dejar el país. A su partida, sus amigos y seguidores hicieron pública la estafa en la que se vieron envueltos. Junto con la carta de despedida de Sarak, El Comercio publicó una nota de Paz Soldán en la que informaba que Sarak se había ausentado del país adeudando diversas sumas de dinero al Centro Esotérico Porvenir, a varias personas de la capital y a él mismo. Agregaba que la publicación de la revista El Loto quedaba suspendida, y con ello las suscripciones que tenían en Perú, Chile, Argentina, Paraguay, Uruguay y Brasil debido a que Alberto de Sarak, sin rendirle cuentas a él como director de la revista, había cambiado la dirección del correo de los canjes internacionales para así interceptar toda la comunicación y el dinero de las suscripciones. ${ }^{65}$

63. "La psiquiatría del doctor Sarak", El Comercio (Lima) 13 de noviembre de 1899: s.f.

64. "Avisos del día”, El Comercio (Lima) 3 de abril de 1900: s.f.

65. "Avisos del día”, El Comercio (Lima) 3 de abril de 1900: s.f. 
Si bien la estafa de Sarak generó desconfianza de la élite médica e intelectual hacia ciertos fenómenos que se encontraban en los márgenes de la ciencia, como era el caso del hipnotismo y espiritismo, la curiosidad del público limeño ante dichos fenómenos no mermó. Así lo demostró la gran recepción del aclamado hipnotizador Onofroff durante su paso por Lima un par de años más tarde. Pese a ello, el espiritismo no alcanzó el nivel de estudio y difusión de otros países de la región, y tras el cierre del Centro Esotérico Porvenir y la revista El Loto no existieron nuevos intentos por generar dichos espacios en la capital peruana.

\section{Conclusión}

La escandalosa huida de Perú fue apenas un accidente más en la larga trashumancia del conde. En efecto, sus tropiezos en Lima no le impidieron en lo más mínimo la prosecución de su empresa de difusión del esoterismo en la región. En los siguientes años continuó viajando por el continente, y fundó centros y revistas en Venezuela, México y Estados Unidos. Sabemos que en 1908 fundó en París un Centre Esotérique Oriental y la revista L'Étoile d'Orient, en cuyas páginas difundió su polémica doctrina. Según algunas fuentes, falleció en 1919 y dejó tres hijos, quienes por un tiempo vivieron en Montevideo.

A través del examen de los trabajos llevados a cabo por Sgaluppi o Sarak en dos ciudades de América Latina, en este artículo hemos intentado ofrecer evidencias documentales de diversos procesos y dinámicas culturales de fines del siglo XIX. Primero, hemos puesto de relieve un agente central en la circulación regional de conocimientos, vocabularios y teorías esotéricas. Sin desestimar las narrativas que insisten en que los canales de circulación de conocimiento obedecieron muchas veces a una jerarquía norte-sur (o centro-periferia), ni poner en entredicho el valor que cupo a los mecanismos internacionales y editoriales (comenzando por el intercambio de revistas) en la labor de expansión de las ciencias ocultas o psíquicas en Latinoamérica, nuestra mirada ha sopesado más bien el rol desempeñado por esoteristas itinerantes que operaron de forma independiente a directivas institucionales. De esa forma, nuestro estudio dialoga con una incipiente tradición investigativa que en los últimos años ha valorizado la importancia cultural y científica de otros agentes heterodoxos (aventureros, falsos médicos, comerciantes, charlatanes) que merced a sus constantes desplazamientos garantizaron, asimismo, la circulación regional de conocimientos u objetos culturales. ${ }^{66}$

En segundo lugar, el estudio del fenómeno transnacional del espiritismo en América Latina, en especial la reconstrucción del itinerario del conde de Das en Argentina y Perú, demuestra cómo en el cambio de siglo los límites de la ciencia aún eran difusos. Como hemos establecido en este artículo, es necesario considerar que idearios heterodoxos como el espiritismo no estaban reñidos con la ciencia de

66. Irina Podgorny, Charlatanería y cultura científica en el siglo XIX (Madrid: Catarata, 2015); Steven Palmer e Iván Molina Jiménez, La voluntad radiante. Cultura impresa, magia y medicina en Costa Rica (1897-1932) (San José de Costa Rica: Editorial de la Universidad Estatal a Distancia, 2004). 
aquel entonces; todo lo contrario, estos tenían la certeza de participar de la cultura científica de su época. Quienes llevaban a cabo dichas prácticas no pregonaban la superioridad de lo sobrenatural, sino que buscaban ensanchar las lindes de la ciencia, de forma tal que esta aceptara en su seno fenómenos que hasta entonces había excluido (por ejemplo, la telepatía o la telekinesis). Tener presente el modo en que el espiritismo participaba de lleno del ideario cientificista del cambio de siglo resulta imprescindible para comprender por qué motivo en Argentina y Perú, entre otros países, personajes como Sgaluppi fueron oídos con respeto por médicos e intelectuales, y representantes de la ciencia académica aceptaron entablar diálogos o debates con los adherentes del espiritismo.

Es evidente que si las iniciativas de Sgaluppi resultaron atractivas para los médicos latinoamericanos no se debió a la afinidad que estos podrían haber hallado entre los procedimientos o técnicas del hipnotizador y aquellos que se realizaban en los laboratorios o institutos galénicos. A pesar de la alusión constante que Sgaluppi esgrimía en sus textos y discursos a "experimentos" u otros conceptos utilizados en la ciencia académica, en realidad su labor principal eran las exhibiciones (de hipnotismo o telepatía) en las cuales lo teatral era un ingrediente ineludible. Dicho, en otros términos, la historia reconstruida aquí vuelve a dar vigor a los ensayos que postulan que a través de ese afán por dar carácter visible o "espectacular" a ciertos fenómenos como la hipnosis, los espiritistas o magnetizadores acercaban a los médicos y otros científicos hechos observables que los profesionales rara vez tenían oportunidad de presenciar en las aulas de medicina o en otros ámbitos académicos. ${ }^{67}$

El tercer elemento tiene que ver con la vertiente comparativa abierta por nuestra exploración. Es evidente que la sólida implantación del espiritismo en Buenos Aires le aseguró al conde de Das un terreno de recepción asaz propicio. Halló en las revistas y cenáculos kardecianos defensores entusiastas de sus iniciativas y difusores obstinados de sus propias creencias. En tal sentido, es muy claro el contraste con lo sucedido años después en Lima. Ante la carencia de una tradición esotérica fue la medicina la máxima aliada del hipnotizador trashumante. En el fervor con que los médicos limeños acompañaron las tareas del conde podemos ver, por supuesto, la comprobación de la endeblez de los límites de la ciencia, ya aludidos. Por el contrario, fueron los médicos higienistas, alineados detrás del Departamento Nacional de Higiene, los principales enemigos de nuestro personaje en Buenos Aires. De todos modos, tal y como ya referimos, es imposible de hablar de respuestas gremiales unívocas. Más que transparentar posicionamientos unánimes, actores como Sgaluppi fuerzan a reconocer el carácter híbrido de profesiones y campos científicos.

67. Acerca de esa hipótesis, véase Sofie Lachapelle, Conjuring Science. A History of Scientific Entertainment and Stage Magic in Modern France (New York: Palgrave Macmillan, 2015). Respecto del ámbito local, véase María José Correa y otros, eds., Ciencia y espectáculo. Circulación de saberes científicos en América Latina, siglos XIX y XX (Santiago: Ocho Libros, 2016). 


\section{Fuentes}

\section{Impresas}

De Sarak, Alberto. Psicología moderna y ciencias ocultas. Lima: Imprenta Liberal, 1899. El Conde de Das (Albert de Sarâk). Montevideo: Imprenta Rural,1906.

Estatutos Generales. Reglamento interior. Instituto Psicológico Argentino. Buenos Aires: Roma, 1892.

Mariátegui, José Carlos. "Un aventurero de folletín”. Escritos juveniles. Tomo 2. Comp. Alberto Tauro. Lima: Biblioteca Amauta, 1915.

Peña y Troncoso, Gonzalo. El dosamantismo es la religión científica, en oposición al ocultismo semita que es una liga de internacional anarquismo. México: Editores J. Guerrero y Cía., 1904.

Primer Congreso Internacional Espiritista. Barcelona: Imprenta de Daniel Cortezo y Ca. Editores, 1888.

\section{Periódicos y revistas}

Anales del Departamento Nacional de Higiene (Buenos Aires) 1891.

Constancia (Buenos Aires) 1892-1893.

El Ateneo de Lima (Lima) 1887.

El Comercio (Lima) 1899-1900.

El Correo Español (Buenos Aires)1892.

El Diario (Buenos Aires)1892.

El Heraldo de Madrid (Madrid) 1890.

El Librepensamiento (Lima) 1900.

El Siglo Futuro (Madrid) 1888.

La Crónica Médica (Lima) 1899.

La Dinastía (Barcelona) 1887.

La Época (Madrid) 1888-1890.

La Iberia (Madrid) 1888.

La Nación (Buenos Aires) 1892.

La Prensa (Buenos Aires) 1892-1893.

La Revista Masónica del Perú (Lima) 1890.

La Tribuna (Buenos Aires) 1892.

\section{Bibliografía}

Brower, Brady. Unruly Spirits. The Science of Psychic Phenomena in Modern France. Urbana: University of Illinois Press, 2010.

Bubello, Juan Pablo. Historia del esoterismo en la Argentina. Prácticas, representaciones $y$ persecuciones de curanderos, espiritistas, astrólogos y otros esoteristas. Buenos Aires: Biblos, 2010. 
Correa, María José y otros. Eds. Ciencia y espectáculo. Circulación de saberes científicos en América Latina, siglos XIX y XX. Santiago: Ocho Libros, 2016.

Chocano, Magdalena. "Lima masónica: las logias simbólicas y su progreso en el medio urbano a fines del siglo XIX”. Revista de Indias 70.249 (2010): 409-444.

Fernández, Mauro. Historia de la magia y el ilusionismo en la Argentina. Buenos Aires: [s.e.], 1996.

Garabedian, Marcelo. "Cosme Mariño y el periodismo del siglo XIX”. Memorias de un hombre mediocre. Cosme Mariño. Buenos Aires: Dunken, 2010.

Gieryn, Thomas. Cultural Boundaries of Science. Credibility on the Line. Chicago: University of Chicago Press, 1999.

Giumbelli, Emerson. O Cuidado dos Mortos: Uma História da Condenação e Legitimação do Espiritismo. Río de Janeiro: Arquivo Nacional, 1997.

Graus, Andrea. "Hypnosis Lessons by Stage Magnetizers: Medical and Lay Hypnotists in Spain". Notes and Records. The Royal Society Journal of the History of Science 71.1 (2017): 141-156.

. "La ciencia del médium. Las investigaciones psíquicas en España". Tesis de doctorado en Historia de la Ciencia, Universidad Autónoma de Barcelona, 2014.

Lachapelle, Sofie. Conjuring Science. A History of Scientific Entertainment and Stage Magic in Modern France. New York: Palgrave Macmillan, 2015.

Luckhurst, Roger. The Invention of Telepathy, 1870-1901. Oxford: Oxford University Press, 2002.

Mülberger, Annette. Ed. Los límites de la ciencia. Espiritismo, hipnotismo y el estudio de los fenómenos paranormales (1850-1930). Madrid: Consejo Superior de Investigaciones Científicas, 2016.

Natale, Simone. "A Cosmology of Invisible Fluids:Wireless, X-Rays, and Psychical Research around 1900". Canadian Journal of Communication 36.2 (2011): 263-275.

Noakes, Richard. "The 'World of the Infinitely Little': Connecting Physical and Psychical Realities Circa 1900”. Studies in History and Philosophy of Science 39.3 (2008): 323-334.

Orbegoso, Arturo. "Espiritismo, locura e intelectuales del 900”. Revista de Psicología de Trujillo 14.1 (2012): 95-105.

Palmer, Steven e Iván Molina Jiménez. La voluntad radiante. Cultura impresa, magia y medicina en Costa Rica (1897-1932). San José de Costa Rica: Editorial de la Universidad Estatal a Distancia, 2004.

Plas, Régine. "Psychology and Psychical Research in France around the End of the 19th Century". History of the Human Sciences 25.2 (2012): 91-107.

Podgorny, Irina. Charlatanería y cultura científica en el siglo XIX. Madrid: Catarata, 2015.

Quereilhac, Soledad. Cuando la ciencia despertaba fantasías. Prensa, literatura y ocultismo en la Argentina de entresiglos. Buenos Aires: Siglo XXI, 2016. 
Roso de Luna, Mario. "Para la historia del ocultismo español. El conde Alberto de Das, un émulo de Cagliostro". Hesperia. Revista teosófica y poligráfica 2.3 (1922): 13-16.

Ruiz, Augusto. Psiquiatras y locos. Entre la modernización contra los Andes y el nuevo proyecto de modernidad. Perú: 1850-1930. Lima: Instituto Pasado \& Presente, 1994.

Sommer, Andreas. "Psychical Research and the Origins of American Psychology: Hugo Münsterberg, William James and Eusapia Palladino". History of the Human Sciences 25.2 (2012): 23-44.

Sosa, Juan José y Pablo Valderrama-Iturbe. "Psychology in Latin America: Historical Reflections and Perspective”. International Journal of Psychology 36.6 (2001): 384-394.

Vallejo, Mauro. El Conde de Das en Buenos Aires, 1892-1893. Hipnosis, teosofía y curanderismo detrás del Instituto Psicológico Argentino. Buenos Aires: Biblos, 2017.

. "Buenos Aires mesmérica. Hipnosis y magnetismo en la cultura y la ciencia de la capital argentina (1870-1900)". Revista Iberoamericana 14.56 (2014): 7-26.

Vicuña, Manuel. Voces de ultratumba: historia del espiritismo en Chile. Santiago:Taurus, 2006.

Winter, Alison. Mesmerized. Powers of Mind in Victorian Britain. Chicago: The University of Chicago Press, 1998.

Wolffram, Heather. The Stepchildren of Science. Psychical Research and Parapsychology in Germany, c. 1870-1939. Amsterdam / New York: Rodopi, 2009. 